\title{
Carnival Classrooms: Sites of Resistance in Secondary Composition Classrooms
}

\author{
Tracee L. Auville-Parks \\ University of Redlands
}

Teachers interested in educational justice seek to create schools as sites of equitable instruction and student development. However, educators must frame lesson content using marginalized student experiences and cultural traditions to counter the dominant hegemony using a critical pedagogical lens to transform critical thinking and engage students to inform and create solutions to public issues. The purpose of this study is to examine the efficacy of using a carnival pedagogy to engage high school students and to strengthen their social-emotional development through mentoring, dialogic or structured conversation, and storytelling to lead them to complete high school. The proposal for this study is currently under revision to clarify the methodology utilized.

Keywords: carnival pedagogy, secondary composition, dialogic mentoring, marginalized student perspective, challenging dominant norms, liberating innovative and critical thought

\section{INTRODUCTION}

The purpose of education remains a debated topic in the United States. American Founding Fathers recognized the need for an educated citizenry but differed over how to achieve that goal. There were proposals made by such luminaries as Thomas Jefferson and Benjamin Rush calling for a national university to educate quality leadership on American soil. Still, the predominant belief was that the government should limit its role in education, rejecting most proposals because decisions regarding education were determined at a local level (Biesta, 2008). Due mainly to 19th-century governmental forces and economic stability, state-sponsored secular education replaced the religiously driven system of the 17th and 18th centuries (Carpenter, 2013). Like Karl Marx, Horace Mann supported state-sponsored education, but Mann promoted the concept of schools that would foster equality, opportunity, and a sense of national identity (Biesta, 2008). However, unlike Mann, Marx believed that education only served the ruling class and perpetuated inequality (Morrow \& Torrres, 1995).

The Supreme Court's decision in Plessy v Ferguson in 1896 suggested a legal difference between White people and Black people was not unconstitutional. As a result, restrictive Jim Crow legislation and separate public accommodations, including schools, based on race became commonplace. From the Brown v Board of Education decision in 1954 to the passage of the Civil Rights Act in 1964, efforts to desegregate led President Johnson to declare that a war on poverty was justified and that education was the way out (Jennings, 2011).

For all that education can do for mainstream K-12 students, research has revealed that the current educational system is sadly deficient for marginalized populations. Marginalized students such as Black, 
Indigenous, or People of Color (BIPOC), Lesbian, Gay, Bisexual, Transgender, or Queer (LGBTQ) students, students with disabilities, and students who are homeless or in foster care do not find the current public educational system supportive of their efforts to earn a diploma (Anderson, 2018; Burghardt, 2020). As a result, marginalized students often feel their efforts to achieve an education undermined.

Campus leaders focused on social and educational justice can counter this by encouraging faculty on K-12 campuses to become culturally competent and transform their classroom practice by applying a critical pedagogical lens to teaching and learning (Ladson-Billings, 1995; Lensmire, 2017; Anderson, 2018; Burghardt, 2020). For example, Fitchett et al. (2012) argue that pedagogies that embrace diversity are humanizing to students, making connections between the classroom and home-life, providing the teacher with glimpses of the students as "subjects rather than objects" (Fitchett et al., 2012, p. 601). In addition, teachers need to connect with and mentor their students and provide culturally relevant lessons that strengthen their social-emotional well-being. Finally, instructors can also help the communities they work in by teaching students to be civic-minded, encouraging them to become actively involved in their communities using collaborative learning projects.

\section{PURPOSE}

The purpose of this study is to examine the efficacy of using Mikhail Bakhtin's carnival pedagogy to engage high school students in ways that strengthen their social-emotional development through mentoring and culturally relevant learning projects. Teachers who share their life experiences with students help them understand the social, economic, and institutional matters that impact the well-being of their community. Still, when teachers encourage civic literacy and participation, they help students feel comfortable participating in class discussions. The hope is that students will understand the importance of active civic literacy and engagement and participate. In addition, I will examine the impact of an applied critical pedagogy on student learning. Teachers need guidance on framing lessons and curriculum from marginalized high school students' perspectives and why it increases academic success. Therefore, using a marginalized student frame to intentionally design a high school composition classroom that encourages dialogue and storytelling to liberate critical thinking so students can resist the status quo.

Creating a classroom where learning is dynamic or active can facilitate and strengthen the teacherstudent relationship, helping students understand that many perspectives are valid and worth critical reflection in writing. To create a classroom with an active learning environment, the teacher must become a fellow learner rather than remain as the arbiter of Truth with a capital T (Sun \& Gao, 2019). Collaborative inquiry projects help students learn about different perspectives (Sun \& Gao, 2019). For example, suppose the teacher curates the content used in collaborative writing projects from newspapers, magazines, literature, current events, graphic novels, and material from the students' cultural backgrounds. In that case, the students will understand that the lived experiences from the past can mirror current student experiences. In this manner, students will discover through their inquiry that they are not alone. According to Allahwala, Bunce, Beagrie, Brail, Hawthorne, Levesque, Mahs, and Visano (2013), teachers interested in building and sustaining relationships, encourage community activism between and among racial groups to increase equity to allow teachers to strengthen bonds that increase educational equity. One result of the teacher's efforts in building such relationships with students is increased graduation rates (Allahwala et al., 2013). One way to strengthen bonds is to create a classroom where power structures are different, such as situating the teacher as a fellow learner and a facilitator rather than an all-knowing expert.

\section{Bakhtin and the Carnival}

One way to disrupt the traditional power structure in the classroom is to challenge how instruction has traditionally been delivered. The carnival for Bakhtin is where all rules and regulations that determine everyday life are postponed, especially all forms of hierarchy in society. Bakhtin (1981) suggests four types of norms in a carnival: 1) people of all levels of society can interact, 2) that unconventional behavior that was otherwise unacceptable is permitted during a carnival, 3) that the accessible and familiar attitude of the carnival enables everything which is usually separate to connect, such as the social hierarchy, and 4) that 
the carnival is a site of ungodliness, of blasphemy, profanity and parodies on things that are sacred. Bakhtin (1981) notes that the carnival was confined in time but not in space, meaning the carnival did not simply exist in a town square but the neighborhoods near the carnival site. The impression that the carnival exists outside a confined space becomes more intriguing when students are connected using smartphones. I would argue most of us are connected to the carnival whether we are physically near it or not.

According to Bakhtin, all the people in a community enjoy the carnival, and, like the carnival, public schools are community-centered, connected. As Lensmire and Snaza (2017) argue, the carnival is where change occurs and that our experiences, while fleeting, help us make sense of the world in which we reside. Educators know that change is constant and that our job remains to help our students because they certainly change. Arguably, technology and global media outlets have blurred the lines between truth and fiction, making critical thinking a vital skill to teach young adults.

Using Bakhtin's carnival as a pedagogy allows students to dialogue with classmates since everyone is a learner. Teaching students to evaluate sources to support a viewpoint helps them participate in society because they feel more confident that they understand their community's issues. Further, using a pedagogy that seeks to include the marginalized voices in a classroom will teach students that all voices are equally important and worth hearing.

\section{SIGNIFICANCE}

Education is one of the means of both perpetuating and improving society. Social justice leaders can help alter and enhance classroom instruction by confronting biases, healing the wounds created by such preferences, and transgressing traditional boundaries of authority and influence to transform schools into sites of liberation. The teacher can begin to achieve this liberation in the classroom by empowering students to choose the subject of a culturally relevant project and then become one of the learners alongside the students (Ladson-Billings, 1995; Riley, 2015). Using a carnival pedagogy entails collaborative involvement in a learning project that is often dialogic. Conversations activate background knowledge that inspires further dialogue, strengthening mastery of the content and pushing the boundaries of what is known (Ladson-Billings, 1995; Lensmire, 1994; Riley, 2015; Freire, 2017). Yet, many teachers still follow what Freire calls the banking system of education, where the teacher deposits the knowledge, and the student memorizes the content for an assessment (Freire, 2017).

However, the banking system does not provide students with opportunities to challenge dominant cultural norms. When teachers become active learners, they model research and writing strategies, helping students untangle and comprehend complex social issues through dialogue (Freire, 2017). For example, the 2001 documentary film Hana's Suitcase brilliantly showcases a collaborative, culturally relevant learning project where the teacher and students uncover the story of a victim of the Holocaust by examining and thinking about the contents of her suitcase. Of course, having the teacher join the students in a learning project goes against the grain for many teachers. Still, by upending the social order that the teacher is the expert, students see an adult willing to participate like a student, inspiring increased student participation.

The setting for this rich engagement is the classroom, of course, but is it a setting that allows for or encourages conversations that push dominant social boundaries when viewed from a marginalized student perspective? Understanding the dynamics of a classroom setting lies at the heart of my project - to create a space where the marginalized point of view is validated. Composition teachers have a unique opportunity to expose high school students to a wide variety of content to practice persuasive, narrative, or expository writing. Having students focus on and write about issues impacting marginalized students can teach them about local and state problems and allow them the opportunity to learn and participate in their community. Teachers need to provide a classroom where students feel their voices are heard to achieve such aims and practice civic literacy skills.

Indeed, educators know that many factors influence a student's ability to graduate. Culturally relevant learning projects are one way to increase students' engagement and understanding of complex social issues.

Yet, research is also showing that race matters in a variety of ways. Teachers who more closely match their students' racial makeup find that the level of school attendance and teachers' expectations of students' 
academic ability and future educational success increases (Rasheed et al., 2020). Unfortunately, the current racial makeup of the teachers coming out of university teaching programs remains White and female; these new teachers must have strategies to increase academic success (Sleeter, 2017). Teachers at all levels of experience must use pedagogies that support all students' social, emotional, and educational growth, especially those marginalized. Therefore, applying a carnival pedagogy, mentoring practices, and collaborative learning projects could increase academic success.

To achieve such success, leaders in educational justice seek to create schools as sites of equitable instruction and student development. Educators must frame lesson content using marginalized student experiences and cultural traditions to counter the dominant hegemony. Teachers should use a critical pedagogical lens to transform critical thinking and engage students to inform and create solutions to public issues. The significance of this study is to examine the impact a teacher can make on marginalized students by applying a critical pedagogy to create a classroom where writing to analyze and critique the status quo is the norm.

\section{CRITICAL PEDAGOGY}

Paulo Freire (2017) argues critical pedagogy impacts student development and allows us to understand how power works in society. Freire believed that students must be free to question and critique dominant social practices as critically involved citizens because that is the purpose of education (Freire, 2017). The connection between Freire and Bakhtin's philosophies is that both men are primarily concerned with how power influences all aspects of society. Both Bakhtin and Freire argue that activating such knowledge is achieved through dialogue. To both men, power should be shared in the classroom, and that dialogue can reveal shared realities and experiences that make everyone responsible for the learning taking place (Bakhtin, 1981; Freire, 2017).

Henry Giroux (2010) also concurred with Bakhtin and Freire, arguing that critical pedagogy allows all students - but especially the marginalized ones - to effect fundamental social change, to rise above existing power structures that promote "conformity, disempowerment" to liberate their moral and civic capacities to think for themselves (p.717). Carnival pedagogy centers around the idea that the average person has knowledge and experience. Therefore, teachers interested in teaching concepts regarding race and racism must be willing to facilitate conversations around sensitive topics to affect change. The Black Lives Matter movement is one such topic that is currently polarizing. Yet, engaging high school students in this topic allows those marginalized to understand that their peers have similar experiences (Bakhtin, 1981; Freire, 2017).

Critical theorists like Bahktin, Giroux, and Freire also believe that unequal social structures of power and reward are inherent in many institutions. Those who benefit from this inequality strive mightily to maintain it (Bakhtin, 1981; Freire, 2017; Giroux, 1983; Morrows \& Torres, 1995). Education can be a great social equalizer if it does not undermine marginalized students' efforts. However, for education to be the national equalizer, teachers must find ways to help students understand the explicit rules, norms, and values as well as the implicit or hidden ones that often highlight or perpetuate inequities inherent in any institutional system such as education (Anyon, 1980; Bakhtin, 1981; Freire, 2017). Often the values and lessons reinforced by the hidden curriculum are status quo, arguably carrying the assumption that these hidden practices and messages do not need to change (Anyon, 1980). Teachers utilizing a critical, carnival pedagogy seek to not only reveal hidden inequities but counteract them through dialogic means to allow marginalized students the opportunity to recognize and rise above perpetuating systems of oppression that concern scholars like Bakhtin and Freire (Bakhtin, 1984; Freire, 2017).

Furthermore, Bakhtin, Freire, and Giroux (1983) argue that to challenge oppressive systems, teachers must educate students about analyzing and critiquing societal practices that perpetuate oppression once recognized. Scholars call this practice a critical literacy skill designed to explore individual and collective problems to arrive at solutions (Bakhtin, 1981; Freire, 2017; Giroux, 1983). Yet, the notion that marginalized students will resist the status quo while in a classroom is difficult to achieve if the impact of marginalization remains unaddressed (Tanner, 2019). However, without the capacity to do this, people 
simply accept messages coming from the dominant society without much thought, thus perpetuating the idea that the purpose of education is only cultural and social reproduction rather than helping marginalized students rise above.

\section{CAPITAL INSECURITY}

To help marginalized students rise above systems of oppression, teachers must help students accrue and replicate capital (Bourdieu, 1986). Capital comes in three forms: economic, cultural, and social, e.g., connections or networks (Bourdieu, 1986). Briefly, teachers and schools can quickly affect cultural capital by providing opportunities for students to attend live theatrical or music performances, visit museums and art galleries, attend science camps, and go on field trips to historic locations to meet local communities' members. Social capital is a network of relationships that enable people to work together more effectively (Bourdieu, 1986). Finally, economic capital refers to the assets that can quickly convert into money. However, what remains essential is that capital, in any form, remains a necessary component in achieving upward mobility.

Leaders in the community must be vested in the idea that educational equity is vital to ensuring upward mobility for all students (Freire, 2017). Yet, because schools remain sites of cultural reproduction, they also remain sites of oppression when staff neglect to strengthen cultural and social capital (Bakhtin, 1981; Bourdieu, 1986; Freire, 2017). Arguably, new teachers learn the basics about how the application of pedagogy can impact social and cultural reproduction, but they often unknowingly perpetuate institutional oppression through social and cultural reproduction. Yet providing opportunities in a carnival setting to learn and challenge these systems is vital to marginalized students because they broaden lived experiences and perspectives - social and cultural capital-which allows them to participate fully in dialogic collaborative learning projects (Bakhtin, 1981; Freire, 2017).

However, broadening lived experiences and perspectives can also help students transition into employment, higher education, or military service (Bahktin, 1981; Freire, 2017; hooks, 2013). Marginalized populations often do not share the wealth generated by their labor or find themselves upwardly mobile as their White peers (hooks, 2013). Therefore, educators must teach students how to participate in society to perpetuate it. Still, as hooks argue, education itself is the practice of freedom. Thus, teachers must engage students in critical thinking, allowing them to learn about the limitations of race, class, culture, liberty, and cooperation to transgress boundaries around those subjects to achieve some sense of personal freedom to rise above oppression. According to hooks (2013), teachers must be actively involved in and committed to transgressing boundaries to help students achieve self-actualization in a post-secondary world.

In addition to active involvement, educational professionals must understand the boundaries and barriers marginalized students face while earning their high school diplomas. Schoolwork is an implied training for connecting to work, and employment and school experiences differ by social class. However, these differences may contribute to the development of social class and ultimately help reproduce the system itself. Suppose we were to think of the US public school system as a whole. An argument could be made that since we graduate most high school seniors and set them on a post-secondary path, we achieve one of education's purposes: to continue the status quo. However, meeting educational disparities head-on impacts teaching and learning, increasing high school graduation and marginalized students' social and cultural capital (Allahwala et al., 2013). Simply put, teaching students about the world they inhabit helps them understand how to participate.

\section{FRAMEWORK}

My research will incorporate Bakhtin's notions of the carnival into pedagogy and classroom space and mentoring strategies to help students resist status quo thinking. According to Berkovich (2014), dialogic mentoring involves developing structured interactions with others that are authentic. Authenticity helps create a classroom where honest reflection is valued and viewed as a tool that can reveal personal truths helpful in building and strengthening student identity development (Berkovich, 2014). For teachers, 
authenticity must involve sharing their true selves with students, which helps create an environment where storytelling is valued for discovery and understanding.

Reflective storytelling is a valuable tool not only to activate prior knowledge but to strengthen relationships. To Bakhtin, dialogic mentoring strategies refer to teaching using narrative storytelling. In addition, the curriculum used during the study will come from a variety of sources such as newspapers, short stories, novels, and college prep material. Students need to examine current events, such as politics, climate change, pop culture, and culturally relevant material to activate background knowledge. The use of storytelling allows students to discuss the carnival-like nature of living in a developed nation and will enable them to examine current events in depth.

Torres (2018) argues that teaching focused on meeting educational standards is essential, of course, but teaching language mechanics to include using dynamic meaning and structure must also be included because language is not static. Torres (2018) argues that a carnival pedagogy is a helpful tool to allow students to examine the "living language or language in use" (p. 3). Moreover, teachers use life experiences so students can learn and question "language and social conventions" that repress and oppress expression (Torres, 2018, p. 3). Finally, teachers can help students develop language skills based on genuine practices and connect the use of language to those in positions of power to challenge the status quo and learn to use the power of language - written or spoken — as a form of action beyond self-empowerment only (Torres, 2018).

\section{PRELIMINARY RESEARCH QUESTIONS}

RQ1: How effective is using a carnival pedagogy to create high school composition classrooms where social, economic, and institutional issues are examined from the perspective of marginalized students.

RQ2: To what degree are the benefits of utilizing dialogic mentoring strategies within a carnival space strengthening the relationship between students and the teacher.

\section{PRELIMINARY RESEARCH METHODOLOGY}

This study will utilize narrative inquiry because storytelling and reflective practices help students understand their burgeoning identity (Dysthe, 2011). Miriam and Tisdell (2016) argue that basic qualitative research helps us understand phenomena in a social setting like a classroom. Providing spaces where students are encouraged to critique a society from a historical, global, national, or local past, current events, or some other artifact not only allows students to recognize and acknowledge wrongdoings but seeks to transform such critiques to reveal innovative solutions. Building a relationship between the teacher and student strengthens a student's identity development and the teacher's praxis (Zachary 2003; Murry \& Malmgren, 2005; O’Conner, Dearing \& Collins, 2011).

According to Savin-Baden and Van Niekerk (2007), storytelling is a "verifying mechanism, as a means of confirming or defending truths" and can be used to encourage students to take up a mode of practice, like storytelling, which is helpful in a composition classroom (pg. 463). Learning comes from living, and knowledge comes from those lived experiences. Carnival pedagogy and storytelling align because both rely on lived experiences to connect with new meanings or strengthen existing understandings through confirmation in the telling.

Yet, narrative inquiry is more than storytelling. Teachers learn from their own lived experiences and apply that knowledge to their pedagogical practices. In educational research, narrative inquiry was used in scholarly undertakings in the 1990s to reveal lived experiences as credible (Connelly \& Clandinin, 1990). Connelly and Clandinin (1990) noted that narrative inquiry has an extensive history inside and outside academia. As a methodology, narrative inquiry is an appropriate tool to understand how our lived experiences impact our educational experiences. Connelly and Clandinin (2006) further posit that knowledge arises from experience, gained individually or socially, to shape our present and interpret our past: 
Bakhtin's carnival theory will also be utilized in this study to create a space where the expectation is to challenge or resist status quo norms. I want to provide a classroom to critically examine historical events such as the Black Lives Movement or issues related to national voting rights or gerrymandering, or the protests following George Floyd's death in May 2020 to reveal how systemic racism perpetually operates. I argue that by collaboratively examining and resisting the status quo norms within a space inspired by Bakhtin's carnival, students can learn to liberate critical thinking in ways that benefit all students, especially marginalized ones. The hope is that students will graduate high school understanding that the true purpose of education goes beyond teaching English and math and includes engaging with others critically to advance principles of equality.

\section{POSITIONALITY AND LIMITATIONS}

At this juncture, I must note my positionality as a White female researcher-teacher. Teachers working with students need to activate prior knowledge to ensure concept attainment (Spires \& Donley, 1998). Storytelling or sharing anecdotes to help students connect academic content to their life strengthens comprehension (Spires \& Donley, 1998). Marginalized students may not share similar life experiences with their teacher because they might come from a household experiencing economic, nutritional, or other insecurities. Yet, educators know that one way of activating that prior knowledge is to share personal anecdotes or stories, values, and assumptions to help students find common ground with their instructor and classmates, establishing and strengthening mentoring bonds (Cunliffe, 2016; Freire, 2017). Indeed, common ground must be located and encouraged rather quickly.

Since I teach English composition to marginalized students, I need to have topics or prompts to explore in writing. Class discussions and readings often center around politics, race, class, and current events from various news media outlets to spark rich debate and dialogue. Although my social and cultural characteristics are an essential part of this study and position me as a cultural insider due to similar cultural, linguistic, and social backgrounds, as a middle-aged, White female high school English composition instructor, many of my life experiences are different from my students. I also recognize that my students, primarily alienated from the public-school setting, now attend a charter school known for credit recovery, viewing me as another White woman they probably cannot trust. Unfortunately for all students, White women disproportionately fill pre-teaching programs, and although efforts to diversify those entering such programs are occurring, change is slow (Sleeter, Neal, \& Kumashiro, 2015). Still, until university schools of education and public-school administrators recruit and hire more teachers of color, White females remain the majority in preservice teaching programs. New teachers must prepare for the student population they teach and know that their race impacts learning and teaching (Anderson, 2018; Gershenson et al., 2018; Gordon et al., 2009).

According to Kaplowitz, Griffin, and Seyka (2019), it is fundamental that educators provide a setting where all students can discuss complex topics. It is equally vital that teachers engage the White students in ways that challenge their assumptions and beliefs about race to dismantle racist tropes critically and purposely in the dominant culture in the US. Tanner (2019) argues that studying the intersection of teaching and race is vital because White people tend to ignore their racial identity leaving the burden of "disrupting [W] hite Supremacy” to BIPOCs (Tanner, 2019, p. 184). Ultimately, my positionality as a White woman will be omitted during this study and not fully explored.

This study focuses on examining what type of classroom space enables students to resist the status quo culture to liberate new ways of thinking and being. Issues related to how my race impacts learning are not in question but are beyond the project's scope at this time. Still, to understand my application of critical pedagogy, I include concepts in my literature review that inform my project, my teaching praxis, and my teaching philosophy. 


\section{LITERATURE REVIEW}

\section{Carnival Theory}

Suppose we agree that the purpose of education is to equalize various playing fields so that each of us has complete access to the fruits of our labor. To achieve this, teachers need to manage more than just teaching and learning, however. Educators must teach all students, especially the most marginalized, that controlling one's labor arguably means having more economic security. Education is one step to achieving such security. Yet Gordon, Iwamoto, Ward, Potts, and Boyd (2009) contend that high school students are not only developing intellect but identities that need mentoring, affirmation, and support, too. Teachers need to mentor students to help them see that those in leadership positions support their social-emotional development and celebrate it, making schools sites where challenging dominant norms is the norm. A literature review on issues relevant to creating a carnival classroom where students write from the point of view of a marginalized population is appropriate to understand how teachers support identity development to empower the learner giving them a sense of agency over their future.

Russian linguist and literary critic Mikhail Bakhtin coined the term carnival to characterize attempts to temporarily destabilize power structures, often seen in carnival settings (Lensmire, 2017). For Bakhtin, the work, usually accomplished in writing, must disrupt and symbolize the carnival (Lensmire, 2017). Thus, those within the carnival space know that conventional rules and order are set aside, the world is turned upside down, and daily life customs are temporarily postponed (Lensmire, 2017). Others have argued that not only are customs temporarily postponed, but Bakhtin's carnival is no longer situated on one temporary site, such as the fairgrounds (Emerson, 2010). Since the lo-fi 2000 election debacle that elevated George $\mathrm{W}$. Bush to the presidency, I would argue that we live in a technology-driven society that creates and perpetuates instant gratification and armchair analyses by someone like Fox's infotainer Tucker Carlson. Thus, in the age of fake news, the carnival never ends. As a result, students no longer grow up in a lo-fi world but need strategies and curriculum tailored to help them understand complex twenty-first-century global issues like climate change or national issues like police brutality, school-to-prison pipelines, and racial inequality. Therefore, teachers must create classrooms where challenging norms using a marginalized student lens must occur, requiring teachers to be knowledgeable about current events to use as teachable moments.

Undoubtedly, these discussions can be tricky, but teachers must provide the setting if we want students to liberate and elevate their critical thinking skills (Ladson-Billings, 1995; Lensmire, 1994; Lensmire \& White, 2017). In university teaching programs, teachers are told that they must remain objective, but objectivity is hard to maintain in a world where the news cycles never end. As a composition instructor, it is my job to expose students to a wide array of texts. These texts are often filled with biases, half-truths, or baseless arguments to provide them with ways writers communicate the good, bad, and ugly to readers. Arguably, students need exposure to more than just objective material to learn how propaganda works to sway public sentiment, such as how supporters and opponents of the Black Lives Matter movement try to subvert messages by utilizing fear as a trope. Further, since students live in the world rather than in some vacuum, they must learn that this carnival classroom doesn't necessarily end after the bell rings.

Bakhtin also posited that communication changes over time depending on the historical context in which a message is uttered. The idea that communication changes support the position that while the historical implications regarding primary texts may be viewed differently, they will still generate social commentary, criticism, and reflection depending on how, when, or why a particular text is presented within a given society (Bakhtin, 1981). By applying Bakhtin's carnival theory to the classroom space, students can feel free to criticize cultural norms and status quo ideology for understanding the world around them and their place in it, which - ultimately-increases student agency (Bakhtin, 1981). Furthermore, these connections are made between people's voices in their daily lives and the "political, historical, and ideological contexts they inhabit," meaning that context is an essential aspect of effective dialogic conversations (Blackledge \& Creese, 2009, p. 237). Conversations in a composition classroom can be challenging and anxiety-inducing because participants share their positions or thoughts on topics, which 
can cause debate and dissent. Yet, once students are given guidelines on discussing and debating with kindness, they must continue to broaden their understanding.

The carnival classroom is a space where teaching and learning are often collaborative - discourse aids in making meaningful connections (Blackledge \& Creese, 2009). Teachers should become participantlearners alongside students and share in the journey of discovery. Classrooms should thus be safe spaces for students to learn and practice understanding concepts in many ways. For example, composition teachers must frontload various concepts to teach students how to convey messages in writing effectively (Lensmire, 1994; Lensmire \& White, 2017). Writers practice writing, and readers help writers hone their craft by engaging with a writer's text to understand various points of view. Writing to create an effective product takes practice, and teachers should provide many opportunities to practice.

The carnival, according to Bakhtin, is the commentary, criticism, and ideals expressed and consumed within the space given - a classroom. A dialogically engaged classroom is where the teacher frontloads content to activate prior knowledge and then poses discussion questions to probe deeper. However, when we dialogue, we learn; and during these discussions, students try out new ideas, grapple with complex or controversial topics, and develop new ideas or a deeper understanding. To translate that new understanding, we often ask students to write about it. Yet, it can be overwhelming and scary to share these new ideas with others when we are unsure of ourselves or our opinions, primarily when discussions center around hot topics like race, class, civic and community involvement, and politics. Alternately, when we try to convey our understanding in a debate, a discussion, or writing, we make mistakes. It is often in our conversations or peer-editing workshops where we get the opportunity to stretch our critical thinking skills.

Yet, when discussing sensitive topics, elements of humor can playfully disrupt authority within the carnival space itself (Lensmire, 2017). To Bakhtin, carnival spaces celebrate the fleeting "liberation from the prevailing truth and established order," marking this idea that social norms, customs, and class structures are suspended (Bakhtin, 1986, p. 10). Researcher Tim Lensmire (2017) argues there are four features of the Bakhtinian carnival: it is inclusive, it is free-spirited, it is outlandish or eccentric, and messages conveyed within the space are often profane. Urban high school students and their teachers may see their classrooms as being carnival sites of interesting, vulgar, and humorous dialogue amongst teachers and students-I know I do. Still, learning can be messy, but the classroom remains a place to try out new ideas and ways of being and knowing.

A carnival pedagogy in the high school composition classroom allows educators to develop deeper mentor connections with students because humor can be a carnival component. Humor, to Bakhtin, is centered on the grotesque, understood as elementary-aged potty humor (Tallant, 2017). This type of crude humor is typically attributed to a child's learning about their body and their relation to others as a means of developing a more profound sense of self (Tallant, 2017). Yet, high school composition classrooms can be sites where crude humor exists, where the "de-crowning of authority" happens when teachers assume the role of learner (Lensmire \& White, 2017, p. 13). If a teacher develops dialogic mentor relationships with students, they tend to be more willing to test their burgeoning writer's voice, deepening their effectiveness as a writer (Bakhtin, 1981). Hopefully, in the spirit of collaboration, students will become more selfconfident in expressing themselves in various ways; and humor, indeed, seems to be the icebreaker to taking risks (Lensmire \& White, 2017).

Moreover, teenage writers make meaning and connect issues locally to more significant global problems within those safe classroom spaces. The carnival can undoubtedly be seen as a space to push against or reject social conventions because initially, it was the place where rules and roles were flipped or suspended. Yet, I argue that the carnival has not left the public arena, especially since Darnella Frazier filmed Officer Chauvin applying deadly force onto Floyd's neck, subsequently killing him (Forliti, 2021). Luckily, Frazier filmed the event so that it could not be erased. Thus, the carnival not only flipped, but Frazier exposed another attempt to brutally erase the experiences Black Americans face at the hands of law enforcement officers.

Teachers utilizing any pedagogy understand that what is defined as preferred knowledge changes over time. The idea that something changes over time is not necessarily a paradox because the paradox is the carnival setting itself. The carnival classroom can be a loud, active learning space whose inhabitants are 
often working collaboratively. Just because a classroom full of students is quiet does not mean learning is taking place, just like a loud classroom does not necessarily mean that education is not taking place. A carnival approach subverts and liberates the dominant class's assumptions through humor and chaos, according to Bakhtin (1986). It is a contradiction to say that Bakhtin's carnival teaches us nothing, when in fact, if you wait for five minutes, it might.

Using a carnival pedagogy in a classroom is challenging because the teacher must add non-canonical texts to enhance composition instruction. Teachers utilize stories to teach various concepts, perhaps scaffolding smaller concepts into larger thematic ones, like character development throughout a book. In addition, Bakhtin fosters the idea of polyphony, which means there are many voices to be heard in a story. Stories, to Bakhtin, make the unreal real and are almost magical in a sense. Schultzman (2002) argues:

Magical realism also works along this fine line, telling stories of protestation by actually immersing readers in the world that is being protested by copying it and critiquing it at the same time. It imitates authority to evoke a kind of surreal, magical world — and impossible or "false" one that points to the truth all the same. Magical realism is a non-direct, nontestimonial way of telling stories... (p. 71)

Schultzman's (2002) comment speaks to my desire to get students interested in critiquing the status quo culture using storytelling. Teachers often use personal anecdotes to get students talking about the issues raised in a novel or character study to increase engagement on matters related to criticizing the status quo. These anecdotes or stories are opportunities that can lead to teachable moments that are unscripted, somewhat improvised, and often humorous. Bakhtin's carnival is not a "spectacle, not something performed by some and watched by others. Instead, the line between spectator and performer is blurred" (Lensmire, 2017 , p. 118). Blurring roles in the classroom between the teacher and student fit perfectly in a firmly rooted pedagogy in collaboration and humorous storytelling. Moreover, unless the teacher is careful, the curated material, euphemisms, or anecdotes may not align with the student's primary culture or language, making concept attainment unintentionally difficult.

One of our goals as educators is to support and guide student development. Educators must teach students how to criticize effectively without offending or traumatizing others. Using principles related to Bakhtin's carnival as a guide, teachers can curate a setting where framing lessons from marginalized students' viewpoints is crucial. Moreover, making that space safe and free from retribution is equally vital. Students are not often told, for instance, that the way US history has been taught in school glosses over, if not erases, issues related to class and race in this country. Yet, our students know that race and class intersect and that their textbooks do not truly address it. Teachers and others who work with students must become culturally competent to increase interest and engagement and use relevant material from the students' primary culture in a safe space to resist status quo ideology and liberate innovative thought freely.

\section{Culturally Relevant Teaching}

Culturally relevant pedagogy (Ladson-Billings, 1995; Irvine, 2010) suggests that learning may vary across cultures, classes, and races. Instructors can improve student success by using what they already know and applying it to other concepts. As a survival strategy, cultural norms are passed down multiple generations, molding behavior, values, and beliefs (Kucan \& Cho, 2018). Learning is often a socially constructed and collaborative process related to students' cultural experiences; if new information is not relevant to their narrative, they will not remember the content learned (Ladson-Billings, 1995; Irvine, 2010). However, if lesson content is contextualized from the marginalized student's perspective, they are less likely to forget it (Ladson-Billings, 1995; Irvine, 2010).

A culturally relevant pedagogue scaffolds lessons on the premise that learning may differ across cultures, enhancing student success (Ladson-Billings, 1995). If the teacher understands their students' cultural background, translating this knowledge into an instructional practice that utilizes their lived experiences is effective (Aronson \& Laughter, 2016). Ladson-Billings (1995) argues that culturally relevant pedagogy, or CRP, should create culturally competent students who can understand and evaluate existing 
social conditions and how those conditions do or do not fit in with the ideals of a multicultural democracy. Using CRP principles in the classroom, students become more engaged in their community (Kucan \& Cho, 2018). And because student engagement has increased, students become aware of how institutionalized racism impacts people in a society and how we can understand various perspectives by utilizing a social justice lens (Kucan \& Cho, 2018).

Ladson-Billings (1995) argues that being culturally competent is defined as those educational professionals who understand the culture in which their students live. To reach students, culturally competent educational professionals must utilize such knowledge and cultural norms, patois, and values as cultural capital. If teachers incorporate facets of their students' culture, they achieve higher levels (LadsonBillings, 1995). Interestingly, teachers who endeavor to fit their students' home culture into the school culture make connections between them and the content taught (Ladson-Billings, 1995). Moreover, LadsonBillings (1995) asserts that attempts to accommodate cultural differences between the student's home-life and school-life help bridge gaps, making learning synchronistic, situating the teacher as an insider of the student's cultural group, a mentorship bond. Of course, strengthening such bonds results in higher academic achievement and a stronger identity, all of which benefit the student.

In an era where students increasingly come from marginalized populations, where disparity exists on all levels, where several cultures are represented in the classroom, it is essential to use all tools at the teacher's disposal to teach content (Irvine 2010). In addition, culturally relevant material connects teachers and students in engaging discussions about historical events that increase students' social-emotional development in the high school setting.

\section{Cultural and Social Reproduction}

According to Bourdieu in 1986, cultural reproduction is the social process through which culture is reproduced across time, primarily through the socializing influence of institutions such as schools. Bourdieu applied the concept of social reproduction to schooling, where these institutions pass along cultural ideas as the foundational support of the dominant or upper class's privileged position. Cultural reproduction is part of a more extensive process of social reproduction through which entire societies and their cultural, structural, and ecological characteristics reproduce through a process that invariably involves a certain amount of social change.

Further, structuralism emerged through Marxist thought regarding social production and the reproduction of class structures (Giroux, 1983). Marxists believed that accumulated skills allow for exploiting one's labor, and the selling of one's labor enables one to move up social ladders, theoretically (Morrow \& Torres, 1995). Conflict theory focuses heavily on the competition for resources between groups (Morrow \& Torres, 1995). Groups will fall into conflict due to the unequal distribution and subsequent struggle for limited resources, power, and status (Morrow \& Torres, 1995). Arguably, consistent competition between groups drives decision-making and interactions.

According to Marxist thought, the Bourgeoisie or upper class uses the Proletariat or working-class members who must sell labor to the Bourgeoisie to survive (Giroux, 1983). Further, the correspondence principle argues a link between the social relations of capitalism and education maintained by authoritarian power structures that give schools a modicum of autonomy while reproducing cultural ideologies (Giroux, 1983). Thus, those at the top of society have very different education and ideological production than those in the working class.

From a Marxist perspective, social reproduction is primarily economic in scope. In a broader sense, however, social reproduction is much more than this, from the shape of religious institutions to language and varieties of music and other cultural products. Schools shape the learning experience by reproducing social and cultural norms, values, and beliefs. According to Bourdieu, cultural reproduction is the social practice through which culture is recreated across generations, often through the socializing influence of major institutions like schools. Bourdieu (1986) applied the concept of cultural reproduction to how social institutions such as schools pass along cultural ideas that support the privileged position of the dominant or upper class. Cultural reproduction is part of a more extensive process of social reproduction. All societies 
and their cultural, structural, and ecological characteristics are reproduced through a process that invariably involves a certain amount of social change.

From a Marxist perspective, social reproduction is primarily economic in scope. In a broader sense, however, social reproduction is much more than this, from the shape of religious institutions to language and varieties of music and other cultural products. Much of social and cultural norms are embedded in the hidden curriculum (Anyon, 1980). Apparent or not, connections made between everyday school or classroom activities often illuminate unequal social and economic structures that negatively and perpetually impact students leading some into what has been called the school to prison pipeline (Barnes, 2018).

Yet as bell hooks posit (2013), marginalized populations often do not share the wealth generated by their labor, and they undoubtedly do not find themselves upwardly mobile. Educators teach students how to participate in society to perpetuate the United States' ideals. Yet, as bell hooks argue in Teaching to Transgress (2013), education itself is the practice of freedom. hooks (2013) writes that teachers must engage students in critical thinking, allowing them to learn about the limitations of race, class, culture, liberty, and cooperation to transgress boundaries around those subjects to achieve some sense of personal control. Individual freedoms are essential when we learn to connect our ideas regarding society and agency holistically through our life experiences - we are who we were because our experiences, thoughts, and actions shape us.

According to hooks (2013), teachers must be actively involved in and committed to helping students achieve self-actualization. To hooks (2013), empowering students means that they participate in and improve the society in which they live. Teaching educational professionals to understand the barriers marginalized students face can help them achieve their high school diploma. Schoolwork is an implied training for connecting to work, and employment and school experiences differ by social class (Anyon, 1980; hooks, 2013). These differences may contribute to the development of the children in each social class and ultimately help reproduce the system itself. Thus, an argument can be made that since we graduate most high school seniors and set them on a post-secondary path, we achieve one of education's purposes: to continue the status quo. Still, pulling the data apart arguably reveals significant disparity among marginalized students. Educational disparities must be met head-on, not only to impact teaching positively but learning as well, to increase high school graduation rates (Allahwala et al., 2013).

\section{Critical Theory}

Currently, teachers face challenges of getting students to understand historical events in ways that lead them to respond to a call for action or be so passionate about a topic that they get involved in civic matters (Meliza \& Meliza, 2010). Arguably, teachers want to inspire students to become involved in civic issues to ensure that those in positions of power do not further marginalize people. Therefore, teachers must challenge students to examine current events critically. For example, incidents like the discovery of 751 unmarked graves of Indigenous children at the Marieval Indian School in Saskatchewan, Canada, in 2021, or the Black Lives Matter protests following the death of George Floyd on Memorial Day 2020, are valuable events to analyze so history will not repeat itself. In addition, such events effectively demonstrate connections and disconnections between public policy, schools, classrooms, and students (Schoen \& Fusarelli, 2008).

Furthermore, cultural differences and tensions are often felt in classrooms, especially across marginalized populations, impacting the pedagogy educators apply (Irvine, 2010). However, research, as well as test results, highlight educational inequities between the quality of instruction received at schools or districts with impoverished populations versus schools whose population holds a higher degree of socioeconomic freedom (Anyon, 1980; Murray \& Malmgren, 2005). In addition to shifting economies and incomes, students of color and students whose primary language is something other than English are a rapidly growing population (Murray \& Malmgren, 2005). With learning gaps widening between students from different cultural backgrounds, teachers need to lessen said gaps (Murray \& Malmgren, 2005).

Yet, at the K-12 level, teachers and schools still educate students in a functionalist manner, and educational gaps exist from the first day of school (Morrow \& Torres, 1995). If students' primary language is not English, educational gaps widen (Blaise, 2018). Indeed, during the No Child Left Behind era of 
educational policies under the second President Bush, educational gaps widened further because test-prep focused on English and Maths, meaning that lessons on subjects such as history, civics, and art were grossly truncated or omitted (Blaise, 2018). From a functionalist standpoint, students are well-taught the rules and norms in the classroom, such as raising a hand before speaking, using an inside voice, following a bell schedule at recess, or being respectful of others. However, teachers often have to gloss over random teachable moments to adhere to district pacing schedules so students will perform well on a high-stakes state test, which ultimately widens educational gaps. Arguably, the transmission of values the US holds dear, like individualism, can cause friction between core values taught at home and in schools. For instance, teaching the value placed in US individualism in classrooms might be seen as counter to the importance a family might place upon their group as a whole. Teachers must keep in mind that our students' dominant culture might be different from our own. We should teach content with those family values in mind to provide an enriching educational experience that challenges student learning without devaluing the home culture (Ladson-Billings, 1995).

Functionalists like Emile Durkheim argue that there are several significant functions associated with education. The first is students' socialization in preschool and kindergarten, where students learn how to behave around others and prepare for the working world (Morrow \& Torres, 1995). In school, students learn the rules and norms of the society they live in via social control. Schools also teach core national values like respect for authority, individualism, conformity. Another manifest function of education is that it transmits the dominant culture and provides upward social mobility (Morrow \& Torres, 1995). Education, too, fulfills latent functions, such as creating and strengthening social networks or political and social assimilations that help shape student identity. The purpose of education, then, becomes much broader than many noneducators understand. Sadly, many teachers either turn a blind eye to this fact or do not provide their students with lessons mindful of cultural differences and celebrate those differences.

Critical theory also helps us understand that the purpose of education is multifaceted. The teachers' task is to teach content that informs and allows marginalized groups to join the status quo culture. Yet, schools must also be a safe space for students to criticize dominant culture to liberate innovative critical thinking. Currently, our nation's fundamental purpose in educating citizens must shift away from outdated patriarchal educational practices to ones that are not only culturally relevant but culturally inclusive and framed from a marginalized students' perspective. Using pedagogical approaches to engage students in culturally relevant ways allows them the safe space to express criticism of dominant norms (LadsonBillings, 1995). If teachers join in the learning process, collaborate with students, and model thinking, reflecting, journaling, and storytelling to liberate prior knowledge and ramp up interest, students acquire agency. Critical theory in education asks teachers to go beyond teaching the existing facts and situate those facts in historical context, between past circumstances and future opportunities. As a result, teachers can help students create a liberatory classroom space where challenging norms from a marginalized student perspective helps students develop understanding and empathy.

\section{Critical Literacy}

To challenge social norms, we must teach students how those norms originated and why. Students must also learn how to participate in their society to perpetuate or change it. On the other hand, students who are passive or uninvolved community members also perpetuate norms. To counter this lack of community involvement, teachers and schools must provide students and their families opportunities to work intentionally for the community's health (Anderson \& Irvine 2013; Charest, 2021). Further, school staff must prioritize and connect ideas about civic literacy and communities to impact social change. The origins of critical literacy come from Frankfort School scholars in the 1920s. Additionally, Paulo Freire expounded on the essential framework of critical literacy, arguing that teachers must provide spaces for students to not only become informed but free to resist dominant cultural norms to liberate a just world (Freire, 2017). Critical literacy skills provide students with exposure to different realities and perceptions to understand their own experience within those power relationships.

To get students vested in the idea that they need to look critically at the dominant culture, teachers need to explore the individual, sociopolitical, economic, and intellectual forces that pressure people in a society 
(Bishop, 2014). Bishop (2014) further argues that teachers have an "ethical imperative to examine the contradictions in society between the meaning of freedom, the demands of social justice, the obligations of citizenship and the structured silence that permeates incidences of suffering in everyday life" (p.52). Teaching critical literacy skills helps students see how authors write to uncover or obfuscate societal contradictions to liberate new modes of thinking and being (Bishop, 2014). Yet, when we talk about educating high school students, we forget that the purpose of education is also to inspire the next generation to step up in our communities to share in (re)vitalization efforts. Educators such as Brian Charest (2021), like others before him, argues that we need to view schools and communities as having a "symbiotic" relationship to see that when we talk about problems with schools or education, we are talking about issues within communities" (Charest, 2021, p. xvii). Arguably, teachers can empower students to see that this interconnected relationship is vital by providing opportunities to learn and actively participate in civics matters.

Creating a classroom of active learners requires pedagogical principles that help guide instruction because being active learners should not equate to a noisy classroom. While there is no single model for using critical literacy, the goal is to help students get involved in civic engagement to create a conscious understanding of one's position within a society and the agency to change it. To critical theorists such as Paulo Freire (2017), teachers must support students as they actively learn and pose problem-solving curricula to allow all classroom members to engage in discussion collaboratively. According to Freire (2017), using a film, recording, poster, or illustration can help the participants focus their dialogic communication. Dialogic communication simply means that the participants justify their positions and actively listen to others' views with the goal of mutual understanding and critical reflection (Bakhtin \& Holquist, 1981; Dysthe, 2011; Freire, 2017). Conversations drive connections fundamental to achieving the community's good health and reflect the interconnected reality of community members. As teachers, we must ensure that our students participate in civic matters to see how connected we are in our communities.

\section{Mentoring}

Teachers must develop mentor-type relationships with students to increase social-emotional development and cultural competence, strengthen self-efficacy, grit, and the motivation to succeed, impacting content mastery, thereby increasing graduation rates (O'Conner et al., 2011; Silver et al., 2005). As previously mentioned, dialogic communication means that participants engage in dialogue to justify their positions and actively listen to others' views with the goal of mutual understanding that leads to critical reflection (Bakhtin \& Holquist, 1981; Dysthe, 2011; Freire, 2017). Moreover, when teachers build relationships with students, they must establish roles and negotiate boundaries and measurable outcomes (Zachary, 2002). Mentors and teachers need to be prepared to nurture growth, ask questions, provide timely feedback, and offer challenging content that helps students stretch academically and personally. However, finding adults willing to mentor or teach marginalized students continues to remain challenging. These populations either do not get sufficient support to graduate college or do not return to their communities to help students who, like them, identify as BIPOC, LGBTQ, or disabled (White, 2008; Jamil, Harper \& Fernandez, 2009).

Students, and especially those from a marginalized population, need educators and mentors to be familiar with where they come from - their culture, norms, traditions, values, etc. Students need adults to understand that cultural norms, often seen as a survival strategy, are passed down multiple generations that subsequently mold behavior, values, and beliefs (Kucan \& Cho, 2018). Learning is often a socially constructed and collaborative process related to students' cultural experiences. If new information is not relevant to their narrative, they will not remember the content learned (Irvine 2010). However, if lesson content is contextualized to the student's culture, they are less likely to forget it (Irvine, 2010).

Developing mentor relationships has shown educators that the learning process is collaborative and reciprocal (Zachary, 2002; Nahmad-Williams \& Taylor, 2015). Students must obtain their education, maintain internal motivation, and identify and use various resources to accomplish objectives (Zachary, 2002). Preparing a mentor relationship requires negotiation. Roles and boundaries must be set so that learning can be reciprocal and outcomes measured (Zachary, 2002; Nahmad-Williams \& Taylor, 2015). 
Mentors need to be prepared to nurture growth, ask questions, provide timely feedback and challenging content (Zachary, 2002; Nahmad-Williams \& Taylor, 2015). Teachers must also provide safe spaces for effective learning (Zachary, 2002; Nahmad-Williams \& Taylor, 2015). If one views a mentor relationship as reciprocal, mentors must purposely develop it, and mentees must determine what they hope to gain from the said relationship (Zachary, 2002; Nahmad-Williams \& Taylor, 2015). The mentor relationship's overall goals must be selected from the outset. Learning targets and objectives must be mapped out, and victories celebrated to maintain an atmosphere of joint trust and respect (Zachary, 2002; Nahmad-Williams \& Taylor, 2015).

Regardless, cultural differences and tensions are still felt in the classroom, especially across marginalized groups, impacting educators' pedagogy. Arguably, teachers can convert negative impacts into positive ones by developing a relationship with students to increase social-emotional development to strengthen self-efficacy, grit, and the motivation to succeed, which increases graduation rates (O'Conner et al., 2011). Undeniably, teachers act as mentors, quasi-parents, advocates, social workers, nurses, and counselors to our students (Alisic, 2012). Man of those roles can impact how effective teachers are at their job because some students need more support than others (Alisic, 2012).

Developing the role of a mentor to create relationships with students emphasizes the collaborative nature of identity development, meaning that students work with mentors to learn and affirm their place within their culture (Zachary, 2002). Moreover, teachers see that when students develop relationships with them, students perform better on assessments. Indeed, social-emotional learning is a practice that has been shown to lead to improved interpersonal skills for both the teacher and student, strengthen relationships, and improve job satisfaction, drive, and performance. Preparing a mentor relationship requires negotiation, setting roles and boundaries, and measurable outcomes (Zachary, 2002; Nahmad-Williams \& Taylor, 2015). Mentors need to be prepared to nurture growth, affirm and support developing student identity, ask questions, provide timely feedback, and offer challenging content that helps students stretch academically and personally.

Leaders need to impart a clear sense of campus values and beliefs that stand up to instances of injustice to promote community activism and advocacy while increasing the representation of BIPOC, LGBTQ, and disabled on campus. Furthermore, mentors who self-identify as belonging to a marginalized group are needed to provide students with similar backgrounds or experiences (Dei \& James, 2002). Mentors must understand that students need an adequate representation of the demographic they identify with on campus. However, finding these educators remains difficult because marginalized populations either do not get sufficient support to graduate college or return to their communities to help students self-identify as BIPOC, LGBTQ, and disabled (Jamil, Harper \& Fernandez, 2009). Assisting community members to attend college and encouraging them to come back to advocate for others, especially if they belong to a traditionally marginalized population, can empower those currently navigating the educational system.

Mentors are necessary to provide marginalized students with examples of folks who have successfully transitioned into the post-secondary world of employment, college acceptance, or vocational training (White, 2008). These practices include strategies to increase student agency by providing students with mentors who have similar schooling or life experiences. In addition, teachers can mentor students by providing culturally relevant lessons that affirm and support developing identities.

When mentoring students, teachers and support personnel need to make content relevant by using culturally and racially appropriate texts to help students achieve academic success and cultural competence. In doing so, teachers impart the idea that students can challenge societal norms, affirm their cultural identity, and develop critical thinking skills necessary to critique and challenge social inequities that institutions, like schools, seem to perpetuate (Young, 2010). Kucan \& Cho (2018) argue that to reach marginalized students effectively, teachers must bring into the classroom the academic skills and concepts needed for them to situate themselves within the social order properly to understand historical events. Teachers who learn about their students' cultures provide a safe place to explore the world around them (Kucan \& Cho, 2018). Furthermore, mentors who authentically share themselves and their lived experiences with students will find them more willing to take risks against existing notions, thus advancing their knowledge base, creating a sense of empathy for the perspectives learned about in class (Kucan \& Cho, 2018). Finally, seeing 
ourselves reflected in the faces of our students can show the students that there are other adults with whom they can relate.

\section{Recognition and Identity Development}

Recognition is the process where we form our identity based on the feedback given by others. Students develop their identity, in part, while in school. When students discover and create their identity and see those who share similar attributes or values depicted negatively, it is harder to see their worth (Alcoff, 2007). Students who identify as members of a marginalized population such as BIPOC, LGTBQ, and disabled must have empathetic mentors willing to advocate on their behalf. Such misrecognition hinders a students' social-emotional development, often leading to psychological harm. By not mutually affirming and normalizing the worth of a marginalized students' identity, students do not achieve parity in their community, impacting participation and lessening representation (Alcoff, 2007).

Deranty and Renault (2007) posit that issues regarding the ethics of recognition are political. However, a scholar like Axel Honneth would like to shy away from discussions of recognition politics because, in his view, social progress is built on the normative expectations that individuals in society hold (Deranty \& Renault, 2007). For my study's purposes, the political nature of recognition is sidelined to focus on the importance of identity recognition for marginalized populations. What is also vital to elucidate is that social progress is understood as a moral assertion because individuals within societies deserve recognition (Deranty \& Renault, 2007).

Theorists argue that recognition is an either-or proposition; either it is a struggle for equal participation or a battle for identity affirmation. Yet, this stance seems to negate or diminish the importance of having an identity that others can affirm to increase equal participation. Alcoff (2007) posits that not only can identities negatively impact participation, but they also "positively and substantively" affect participation as well (Alcoff, 2007, p. 257). Once meeting affective needs, students need others to recognize their essential autonomy, which increases their self-confidence, making ethics of recognition a fundamental social justice issue because without developing "social autonomization," students feel a lack of agency that can negatively impact self-esteem and academic success (Deranty \& Renault, 2007, p. 97).

Moreover, Gordon, Iwamoto, Ward, Potts, and Boyd (2009) argue that identities are not simple constructions that only influence participation. When Black adults mentor Black males in middle school specifically, academic achievement increases (Gordon et al., 2009). According to Gershenson, Hart, Hyman, Lindsay, and Papageorge (2018), having same-race teachers for K-12 students increases socialemotional development, positively impacting academic achievement. Indeed, an acknowledgment that race impact identity development, mentoring, and learning, especially for BIPOC, LGBTQ, and disabled students, indicates there is a need for more research, although several studies support the argument that race matters in many respects (Deranty \& Renault, 2007; Gordon et al., 2009; Gershenson et al., 2018). Students' recognition in society helps them form and (dis)affirm their identity by placing a value accorded to them as individuals by others. Again, having adequate representation of a marginalized population on campus willing to mentor students who are considered part of a marginalized community will strengthen the student's social-emotional development.

Representing marginalized people on school campuses is vital to campus leaders. The lack of such participants means there are not enough mentors to develop a positive sense of identity. For young adults, validation is one key in forming a positive self-image. Campus staff wants to increase the number of people who identify as members of a marginalized population and are willing to mentor students to improve positive educational outcomes (Gordon et al., 2009). It is vital to co-construct an educational mentor process whereby teachers and students focus on dialogue, reflection, and generating new knowledge through personal growth, self-affirmation, and actualization to recognize and represent marginalized groups (Gordon et al., 2009). Leaders that actively work to ensure social justice values like equity, access, diversity, participation are followed and sustained by engaging all students, faculty, and the community are necessary. Dialogic mentoring is a strategy that works for all levels of learners strengthening the whole student; such mentoring is a continual transfer of power toward those traditionally marginalized who often lack it. 


\section{Student Agency}

Indeed, marginalized students often lack real and perceived power. Yet, teachers can help students position themselves to achieve power by allowing students more control over their learning in the classroom (Cook-Sather, 2019). Giving students a voice is a start toward giving them agency. According to Bandura (2001), an agent is someone who intentionally makes things happen by their actions. Further, Bandura (2001) argues that "agency embodies the endowments, belief systems, self-regulatory capabilities, and distributed structures and functions through which personal influence is exercised, rather than residing as a discrete entity in a particular place" (p. 2). An agent can make things happen by exercising their actions (Bandura, 2001). The core features of agency enable people to play a part in their development, adapt when necessary, and self-renew when times change (Bandura, 2001).

Student agency, linked to self-regulated learning, is where students become leaders of their learning processes by developing the skills needed to plan, oversee, and assess their knowledge (Moses, Rylak, Reader, Hertz, \& Ogden, 2020). Additionally, Moses et al. (2020) argue that student agency often documents the structures and contexts supporting student development. Consequently, Moses et al. (2020) define student agency as a student's ability to act in ways that exhibit their own choices in their learning. Student agency also involves the conscious use of a student's beliefs to self-regulate and reflect on their ability to control and take ownership of their education.

Pedagogically speaking, the decisions and revisions to support student agency are largely constructivist. For example, teachers typically personalize topics and ask students to self-motivate while investigating a subject to create a product that assesses the learning. Thus, the teacher's role is as a "facilitator of learning" rather than the "dispenser of knowledge" (Moses et al., 2020, p. 214). Opportunities for collaboration are also a sound pedagogical strategy for building and supporting student agency and identity development in a classroom (Mameli, Grazia, Passini, \& Molinari, 2020). Teachers who provide students with authentic community engagement allow them to comprehend the interconnected nature of people living in a society.

\section{Social-Emotional Development}

According to Dods (2012), students want interaction with their teachers to form "meaningful connections" (Dods, 2012, p. 82). There are four elements of a supportive relationship: 1) the leader of the interaction needs to be teacher-driven, 2) the quality of the exchange must be authentic, and empathy must drive connections, 3) the interaction between teacher and student must be active and fluid; if a student is visibly bothered the teacher should step up and inquire why, and 4) the relationship is "individualized" meaning that students are treated on their terms as an individual (Dods, 202, p. 84).

When teachers view students individually, holistically, and exhibit genuine care for those who experience trauma, students tend to have more positive outcomes and strengthen resilience (Dods, 2012; Kuperminc et al., 2019). Research also highlights the efficacy of using group mentoring to increase student resiliency (Kuperminc et al., 2019). Staff focused on a project-based, collaborative curriculum that is culturally relevant also helps classmates' mentor each other to strengthen resiliency and social-emotional development (Kuperminc et al., 2019). Thus, supporting the social and emotional health of students is a fundamental practice.

\section{Curated Curriculum}

The courses used in the study are inspired by and incorporate the Expository Reading and Writing Course, commonly known as ERWC. These are courses designed to strengthen college-level composition skills so that students are prepared for post-secondary academic writing. Teachers are trained by faculty from the UC/CSU system to teach composition using historical or current events as a platform to think about and discuss the various facets of topics critically. Additionally, teachers instruct students to read with and against the grain to discover what writers do to craft messages.

As a result, this study will incorporate supplemental texts following the ERWC style of incorporating op-ed pieces as a starting point for discussion. Readings will be assigned from texts like Stamped from the Beginning by Ibram X. Kendi, Freedom Writers by Erin Gruwell, Night by Elie Wiesel, Farewell to Manzanar by Jeanne Wakatsuki Houston and James D. Houston, and plays like Raisin in the Sun by 
Lorraine Hansberry and Death of a Salesman by Arthur Miller. Students will select culturally relevant topics to examine current or historical events using newspapers, magazines, art, music lyrics, advertisements, and primary source material. Students will write using prompts, in-class discussions, or readings that focus on current issues related to race and class, civics and community, protest movements like Black Lives Matter, police reform, or the 1619 Project, from a marginalized student perspective. Additionally, culturally relevant and historical material will come from the local San Manuel Band of Indians known as the Serrano Indians, the original inhabitants of a substantial amount of land in Southern California. The educational goal remains to enable students to become critical writers and thinkers about issues that impact a marginalized person in society, using standards-based instructional guidance.

\section{Participants}

The participants are 10th and 12th grade English composition students at a public charter school in Southern California. Typically, the students are Hispanic and African American, with roughly 2-3 White students per class. Most students come from homes that experience economic and nutritional insecurities, have multiple generations living in the house, care for an aging or sick relative, or are English language learners. Often students have been kicked out of their previous school or are on probation of some kind and need a place to catch up academically. Since my students come from traditionally marginalized populations, framing lessons from that perspective will help them activate prior knowledge and succeed in the classroom. In addition, students can relate to the culturally relevant content highlighted using the researcher's curated curriculum.

Students will participate in unstructured pre-and post-interviews of high school English students from my public charter school in southern California. I have given the school the following pseudonym: So. Cal. Public Charter School or SCPCS. Study participants will range in age from 18- to 20-years old and come from all socio-economic levels. The students will participate in semi-structured interviews to ascertain how their past school experiences have impacted their ability to graduate on time with their peers and what they believe they need to achieve success. I will analyze the interviews to uncover the categories or themes revealed within the content (Merriam \& Tisdell, 2015). Using a content analysis approach of organizing interview data by themes will allow me to uncover instances where pedagogy, mentoring, or the curriculum itself helps students resist status quo thinking and liberate innovative thinking. Analysis of interview transcripts will determine the initial list of concepts to systematically explore during subsequent interviews (Merriam \& Tisdell, 2015).

In addition to interviewing former students, I will have current students journal their reflections about the lesson content or activity to try to uncover what works and what does not. I supplement the approved curriculum from the CSU/UC Expository Reading and Writing Curriculum, or ERWC, with current events. I keep a journal on what worked and did not work to execute a lesson, critique the execution, and record any positive or negative impressions useful for re-teaching. Reading student journals will help me (re)assess the curated classroom space and lesson objectives' efficacy. Implications from Burns' (2020) research suggest that journaling empowers and inspires participants to reflect critically on lesson objectives scaffolded into the coursework (Burns, 2020). For teachers, journaling helps prevent hidden biases or curriculum from arising, making reflective writing a critical tool for teachers and students (Anyon, 1980).

\section{CONCLUSION}

To find solutions to complex problems, we need innovative thinkers in our society. If we do not cultivate them in schools, we fail to achieve one fundamental goal: social reproduction (Freire, 2017; Giroux, 2010). Yet, teaching students to be civic-minded and engaged in their community can be difficult if teachers continue to perpetuate the status quo because the status quo tends to ignore those marginalized (Freire, 2017). Since I teach mostly marginalized urban students, I want them to be aware that they have agency and can actively learn how to use their agency to participate in their school community and beyond. The task for secondary teachers is to help students understand how and why they should participate in local, state, and national civic activities like voting, registering for selective service, and jury duty (Charest, 2021). 
Teachers need to mentor secondary students in learning about civic matters to impress upon them that a participatory government needs civic-minded community members engaged in actively promoting community involvement to better society. Teachers have the opportunity, and the obligation really, to impress upon students that democracy is participatory, that communities large and small need their citizens engaged in public affairs (Charest, 2021). Still, to do this, teachers require students to grasp the concept that they must participate in meaningful ways. Yet, I find that students are afraid to look ignorant- "stupid" is the word they use - so silence reigns supreme in the classroom. For example, during the fall semester of 2020, at the height of the national election cycle that saw Joseph Biden defeat Donald Trump and a rampant covid pandemic that killed Americans by the thousands, students had definite opinions regarding who they wanted as president. Yet, students did not know where to begin to cast a vote.

As a person interested in politics from a young age, I was willing to vote and learn along the way. My students, however, tend to do nothing when unsure of how to act or what to do. To help them conquer their fear, I brought in my sample ballot and voter's pamphlet. By the end of January 2021, we had watched, discussed, and learned about issues currently impacting voters, and students were willing to share their beliefs. The big takeaway from this experience was that students need teachers ready to be authentic, share opinions in ways that do not belittle those with differing views, and explain the issues from as many sides as possible. I have taught all my students that I am as biased as anyone. It is difficult to remove my personal bias to be truly objective, but I try to provide students with opportunities to engage with civic issues.

My takeaway from this ongoing project is that a high level of teacher engagement and mentoring is needed within a classroom to inform students on current community matters and encourage innovative critical thinking. Teachers must also be willing to express personal views in ways that explain but do not disparage opposing opinions, share how we come to hold certain beliefs, and politely dissent. In addition, students need to ascertain real from fake news to make informed decisions and help them empathize with others to see how those in positions of power maintain it at the expense of others. Finally, as my study progresses, I hope to uncover what makes a successful classroom space a place to learn to resist dominant cultural norms and challenge social structures to liberate critical and innovative thought.

\section{REFERENCES}

Alcoff, L.M. (2007). Fraser on Redistribution, Recognition, and Identity. European Journal of Political Theory, 6(3), 255-265. https://doi.org/10.1177/1474885107077305

Alisic, E. (2012). Teachers' Perspectives on Providing Support to Children After Trauma: A Qualitative Study. School Psychology Quarterly, 27(1), 51-59. $\mathrm{http} / / / \mathrm{dx}$.doi.org.ezproxy.redlands.edu/10.1037/a0028590

Allahwala, A., Bunce, S., Beagrie, L., Brail, S., Hawthorne, T., Levesque, S., . . . Visano, B. (2013). Building and Sustaining Community-University Partnerships in Marginalized Urban Areas. Journal of Geography, 112(2), 43-57. https://doiorg.ezproxy.redlands.edu/10.1080/00221341.2012.692702

Anderson, M.B. (2018). A Seat at the Table: African American Youth's Perceptions of K-12 Education. UNCF.

Anyon, J. (1980). Social Class and the Hidden Curriculum of Work. Journal of Education, 162(1), 67-92. https://doi.org/10.1177/002205748016200106

Aronson, B., \& Laughter, J. (2016). The Theory and Practice of Culturally Relevant Education: A Synthesis of Research Across Content Areas. Review of Educational Research, 86(1), 163-206. https://doi.org/10.3102/0034654315582066

Bakhtin, M. (1984). Rabelais and His World. H. Iswolsky, Trans. Midland.

Bakhtin, M., \& Holquist, M. (1981). Dialogic Imagination: Four essays. University of Texas Press.

Bakhtin, M.M. (1986). Speech Genres and Other Late Essays (V.W. McGee, Trans.). University of Texas Press.

Bandura, A. (2001). Social Cognitive Theory: An Agentic Perspective. Annual Review of Psychology, 52(1), 1-26. https://doi.org/10.1146/annurev.psych.52.1.1 
Bandura, A. (2002). Self-Efficacy in Changing Societies. Cambridge UP.

Barnes, M. (2018). Reducing Racial Inequalities in Adulthood Arrest by Reducing Inequalities in School Discipline: Evidence from the school-to-prison pipeline. Developmental Psychology, 54(12), 2328-2340. https://doi.org/10.1037/dev0000613

Biesta, G. (2008). Good Education in an Age of Measurement: On the Need to Reconnect with the Question of Purpose in Education. Educational Assessment, Evaluation and Accountability, 21(1), 33-46. https://doi.org/10.1007/s11092-008-9064-9

Bishop, E. (2014). Critical Literacy: Bringing Theory to Praxis. Journal of Curriculum Theorizing, 30(1), 51-63.

Blackledge, A., \& Creese, A. (2009). Meaning-Making as Dialogic Process: Official and Carnival Lives in the Language Classroom. Journal of Language, Identity, and Education, 8(4), 236-253. https://doi.org/10.1080/15348450903130413

Bourdieu, P. (1986). The Forms of Capital. In J. Richardson (Ed.), Handbook of Theory and Research for the Sociology of Education. Greenwood Press.

Burghardt, D. (2020). Critical Pedagogy According to Marx: On Western Marxism, the New Marx Reading and Its Connections to Pedagogy 1. Knowledge Cultures, 8(1), 11-25. https://doi.org/10.22381/KC8120202

Burns, E.A. (2020). Reflective School Library Practitioners: Use of Journaling to Strengthen Practice. School Library Research, 23, 1-16.

Carpenter, J. (2013). Thomas Jefferson and the Ideology of Democratic Schooling. Democracy \& Education, 21(2).

Charest, B. (2021). Teaching Civic Literacy in Schools: Reviving Democracy and Revitalizing Communities. Teachers College Press.

Clandinin, D.J., \& Rosiek, J. (2006). Mapping a Landscape of Narrative Inquiry: Borderland Spaces and Tensions. In D.J. Clandinin (Ed.), Handbook of narrative inquiry: Mapping a methodology (pp. 35-75). SAGE.

Connelly, F.M., \& Clandinin, D.J. (1990). Stories of Experience and Narrative Inquiry. Educational Researcher, 19(5), 2-14. doi: 10.3102/0013189x019005002

Connelly, F.M., \& Clandinin, D.J. (2006). Narrative Inquiry. In J.L. Green, G. Camilli, \& P. Elmore (Eds.), Handbook of Complementary Methods in Education Research (3rd ed., pp. 477-487). Lawrence Erlbaum.

Cook-Sather, A. (2020). Student Voice Across Contexts: Fostering Student Agency in Today's Schools. Theory Into Practice, 59(2), 182-191. https://doi.org/10.1080/00405841.2019.1705091

Cunliffe, A. (2016). On Becoming a Critically Reflexive Practitioner Redux: What Does it Mean to be Reflexive? Journal of Management Education, 40(6), 740-746. https://doi.org/10.1177/1052562916668919

Dei, G.J. (2007). Schooling as Community. Journal of Black Studies, 38(3), 346-366. https://doi.org/10.1177/0021934707306570

Dei, G.J. (2008). Schooling as Community: Race, Schooling, and the Education of African Youth. Journal of Black Studies, 38(3), 346-366. https://doi.org/10.1177/0021934707306570

Dei, G.J.S., \& James, I.M. (2002). Beyond the Rhetoric: Moving from Exclusion, Reaching for Inclusion in Canadian Schools. Alberta Journal of Educational Research, 48(1), 61-87.

Deranty, J., \& Renault, E. (2007). Politicizing Honneth's Ethics of Recognition, 88(1), 92-111. doi:10.1177/0725513607072459

Dods, J. (2013). Enhancing Understanding of the Nature of Supportive School-based Relationships for Youth Who have Experienced Trauma. Canadian Journal of Education, 36(1), 71-95.

Dysthe, O. (2011). Opportunity Spaces for Dialogic Pedagogy in Test-Oriented Schools: A Case Study of Teaching and Learning in High School. In E. White \& M. Peters (Eds.), Bakhtinian Pedagogy: Opportunities and Challenges for Research, Policy and Practice in Education Across the Globe (pp. 69-88). Peter Lang Pub. 
Emerson, C. (2010). All the Same the Words Don't Go Away: Essays on Authors, Heroes, Aesthetics, and Stage Adaptations from the Russian Tradition. Academic Studies Press.

Fitchett, P., Starker, T., \& Salyers, B. (2012). "Examining Culturally Responsive Teaching Self- Efficacy in a Preservice Social Studies Education Course. Urban Education, 47(3), 585-611. https://doi.org/10.1177/0042085912436568

Forliti, A. (2021, June 11). Teen Who Recorded Floyd's Arrest, Death wins Pulitzer Nod. AP NEWS. Retrieved from https://apnews.com/article/pulitzer-prize-2021-citation-darnella-frazier-georgefloyd-dce128319a373ef5360237f4c80dc9bb

Freire, P. (2017). Pedagogy of the Oppressed. Penguin Classics.

Gershenson, H., Holt, S., \& Papageorge, N. (2016). Who Believes in Me? The Effect of Student-Teacher Demographic Match on Teacher Expectations. Economics of Education Review, 52, 209-224.

Gershenson, S., Hart, C.M., Hyman, J., Lindsay, C., \& Papageorge, N. (2018). The Long Run Impacts of Same-Race Teachers. National Bureau of Economic Research. https://doi.org/10.3386/w25254

Giroux, H. (1983). Critical Theory and Educational Practice. UNSW Press.

Giroux, H. (2001). Theory and Resistance in Education: Towards a Pedagogy for the Opposition. Bergin \& Garvey.

Giroux, H. (2010). Rethinking Education as the Practice of Freedom: Paulo Freire and the Promise of Critical Pedagogy. Policy Futures in Education, 8(6), 715-721. https://doi.org/10.2304/pfie.2010.8.6.715

Gordon, D.M., Iwamoto, D., Ward, N., Potts, R., \& Boyd, E. (2009). Mentoring Urban Black Middle School Male Students: Implications for Academic Achievement. The Journal of Negro Education, 78(3), 277-289.

Hooks, B. (2014). Teaching to transgress. Routledge.

Howard, T. (2003). Culturally Relevant Pedagogy: Ingredients for Critical Teacher Reflection. Theory Into Practice, 42(3), 195-202. https://doi.org/10.1207/s15430421 tip4203_5

Irvine, J.J. (2010). Culturally Relevant Pedagogy. The Education Digest, 75(8), 57-61.

Jamil, O.B., Harper, G.W., \& Fernandez, M.I. (2009). Sexual and Ethnic Identity Development Among Gay-Bisexual-Questioning (GBQ) Male Ethnic Minority Adolescents. Cultural Diversity \& Ethnic Minority Psychology, 15(3), 203-214. https://doi.org/10.1037/a0014795

Jennings, J. (2011). Get the Federal Government Out of Education? That Wasn't the Founding Fathers' Vision. The Education Digest, 77(4), 55-62.

Kaplowitz, D.R., Griffin, S.R., \& Seyka, S. (2019). Race Dialogues: A Facilitator's Guide to Tackling the Elephant in the Classroom. Teachers College Press.

Kucan, L., \& Cho, B. (2018). "Were There Any Black People in Johnstown?" An Investigation of Culturally Relevant Pedagogy in Service of Supporting Disciplinary Literacy Learning in History. Urban Education. https://doi.org/10.1177/0042085918804011

Kuperminc, G.P., Seitz, S., Joseph, H., Khatib, N., Wilson, C., Collins, K., \& Guessous, O. (2019). Enhancing Program Quality in a National Sample of After-school Settings: The Role of YouthStaff Interactions and Staff/Organizational Functioning. American Journal of Community Psychology, 63(3-4), 391-404. https://doi.org/10.1002/ajcp.12329

Ladson-Billings, G. (1995). Toward a Theory of Culturally Relevant Pedagogy. American Educational Research Journal, 32(3), 465-491. htts://doi.org/10.3102/00028312032003465

Lensmire, T. (1994). Writing Workshop as Carnival: Reflections on an Alternative Learning Environment. Harvard Educational Review, 64(4), 371-391. https://doi.org/10.17763/haer.64.4.u1q517012jt516t6

Lensmire, T. (2017). Too Serious: Learning, Schools, and Bakhtin's Carnival. In E.J. White \& M.A. Peters (Eds.), Bakhtinian Pedagogy. Peter Lang.

Lensmire, T., \& White, E. (2017). Special Issue: The Carnivalesque and Democracy Across Diverse Contemporary Learning Contexts: A 'Wrong-Headed Reading of Carnival, Democracy, and Education. Knowledge Cultures, 5(3), 11. https://doi.org/10.22381/kc5320171 
Lensmire, T.J., \& Snaza, N. (2017). Saint Bakhtin, Porous Theorizing, and Proceeding Nonetheless. Dialogic Pedagogy: An International Online Journal, 5. doi: 10.5195/dpj.2017.221

Mameli, C., Grazia, V., Passini, S., \& Molinari, L. (2021). Student Perceptions of Interpersonal Justice, Engagement, Agency, and Anger: A Longitudinal Study for Reciprocal Effects. European Journal of Psychology of Education. doi: 10.1007/s10212-021-00559-9

Merriam, S.B., \& Tisdell, E.J. (2015). Qualitative Research: A Guide to Design and Implementation. John Wiley \& Sons.

Morrow, R., \& Torres, C. (1995). Social Theory and Education: A Critique of Theories of Social and Cultural Reproduction. State University of New York Press.

Moses, L., Rylak, D., Reader, T., Hertz, C., \& Ogden, M. (2020). Educators' Perspectives on Supporting Student Agency. Theory Into Practice, 59(2), 213-222. https://doi.org/10.1080/00405841.2019.1705106

Murray, C., \& Malmgren, K. (2005). Implementing a Teacher-Student Relationship Program in a HighPoverty Urban School: Effects on Social, Emotional, and Academic Adjustment and lessons learned. Journal of School Psychology, 43(2), 137-152.

Nahmad-Williams, L., \& Taylor, C. (2015). Experimenting With Dialogic Mentoring: A New Model. International Journal of Mentoring and Coaching in Education, 4(3), 184-199. https://doi.org/10.1108/IJMCE-04-2015-0013

O’Conner, E., Dearing, E., \& Collins, B.A. (2011). Teacher-Child Relationship and Behavior Problem Trajectories in Elementary School. American Educational Research Journal, 48(1), 120-162.

Rasheed, D., Brown, J., Doyle, S., \& Jennings, P. (2020). The Effect of Teacher-Child Race/Ethnicity Matching and Classroom Diversity on Children's Socioemotional and Academic Skills. Child Development, 91(3), e597-e618. https://doi.org/10.1111/cdev.13275

Riley, K. (2015). Enacting Critical Literacy in English Classrooms: How a Teacher Learning Community Supported Critical Inquiry. Journal of Adolescent \& Adult Literacy, 58(5), 417-425. https://doi.org/10.1002/jaal.371

Savin-Baden, M., \& Niekerk, L.V. (2007). Narrative Inquiry: Theory and Practice. Journal of Geography in Higher Education, 31(3), 459-472. https://doi.org/10.1080/03098260601071324

Schoen, L., \& Fusarelli, L.D. (2008). Innovation, NCLB, and the Fear Factor: The Challenge of Leading 21st-Century Schools in an Era of Accountability. Educational Policy, 22(1), 181-203. https://doi.org/10.1177/0895904807311291

Schutzman, M. (2002). Guru Clown, or Pedagogy of the Carnivalesque. Theatre Topics, 12(1), 63-84. https://doi.org/10.1353/tt.2002.0006

Silver, R.B., Measelle, J.R., Armstrong, J.M., \& Essex, M.J. (2005). Trajectories of Classroom Externalizing Behavior: Contributions of Child Characteristics, Family Characteristics, and the Teacher-Child Relationship During School Transition. Journal of School Psychology, 43(1), 3960 .

Sleeter, C. (2017). Critical Race Theory and the Whiteness of Teacher Education. Urban Education, 52(2), 155-169. https://doi.org/10.1177/0042085916668957

Sleeter, C.E., Neal, L.V.I., \& Kumashiro, K.K. (2015). Diversifying the Teacher Workforce: Preparing and Retaining Highly Effective Teachers. Routledge.

Spires, H.A., \& Donley, J. (1998). Prior Knowledge Activation: Inducing Engagement with Informational Texts. Journal of Educational Psychology, 90(2), 249-260. https://doi.org/10.1037/00220663.90.2.249

Sun, Y., \& Gao, F. (2019). Exploring the Roles of School Leaders and Teachers in a School-Wide Adoption of the Flipped Classroom: School Dynamics and Institutional Cultures. British Journal of Educational Technology, 50(3), 1241-1259. https://doi.org/10.1111/bjet.12769

Tallant, L. (2017). Embracing the Carnivalesque: Young Children's Humor as Performance and Communication. Knowledge Cultures, 5(3), 71-84. https://doi.org/10.22381/KC5320176

Tanner, S. (2019). Whiteness is a White Problem: Whiteness in English Education. English Education, $51(2), 182-199$. 
Torres, M. (2018). Subverting Lifeless Language Teaching Mandates with Bakhtinian Carnival Pedagogy [Paper presentation]. Teacher Action Research to Counter De-professionalizing Education Reforms, Orel, Russia.

White, O. (2008). Ethnic Identity Development Among Adolescents in Foster Care. Child \& Adolescent Social Work Journal, 25(6), 497-515. https://doi.org/10.1007/s10560-008-0140-2

Young, E. (2010). Challenges to Conceptualizing and Actualizing Culturally Relevant Pedagogy: How Viable is the Theory in Classroom Practice? Journal of Teacher Education, 61(3), 248-260. https://doi.org/10.1177/0022487109359775

Zachary, L.J. (2002). The Role of Teacher as Mentor. New Directions for Adult and Continuing Education, (93), 27-38. https://doi.org/10.1002/ace.47 